\title{
Estado De Calamidade Pública Enquanto Possibilidade De Limite Circunstancial Implícito De Emenda Constitucional
}

\author{
Roberto Leonardo da Silva Ramos* \\ Universidade Federal do Sul e Sudeste do Pará, Faculdade de Direito, Marabá-PA, Brasil. \\ iD https://orcid.org/oooo-0002-2316-8696
}

\begin{abstract}
Resumo: O estado de calamidade pública foi decretado pela primeira vez no Brasil em nível nacional no mês de março de 2020, decorrente da proliferação do Coronavírus, causador da Covid-19. A dinâmica social é sensivelmente afetada, dada as restrições estabelecidas pelo poder público nas esferas federal, estadual e municipal. Visando regulamentar a nova realidade, constata-se ampla produção normativa, a exemplo de leis, decretos e até mesmo de emenda constitucional, bem como a judicialização de temas pertinentes ao enfrentamento dessa emergência de saúde pública, instaurando-se uma crise institucional. Nesse contexto, indagou-se acerca da possibilidade de reconhecimento de limite circunstancial implícito ao poder de emenda da Constituição, especialmente em casos de decretação do estado de calamidade pública. $\mathrm{O}$ artigo utilizou-se do método de abordagem dedutivo, de procedimentos comparativo, bibliográfico e documental, realizando estudo na área constitucional a partir de atos normativos, jurisprudências e doutrinas. Partiu-se dos institutos dos poderes constituinte e constituído, evidenciando seus limites expressos e implícitos como instrumentos eficazes na manutenção da ordem constitucional que corresponda às expectativas da soberania popular, para concluir pela possibilidade da irreformabilidade circunstancial implícita da Constituição Federal na vigência do estado de calamidade pública.
\end{abstract}

Palavras-chave: Emenda constitucional. Calamidade pública. Limite circunstancial implícito.

* Professor da Universidade Federal do Sul e Sudeste do Pará (UNIFESSPA). Doutor e Mestre em Ciências Jurídicas pela Universidade Federal da Paraíba (UFPB). Líder do Grupo de Pesquisa Direito e Sociedade. E-mail: robertoleonardo@mouraramos.com.br

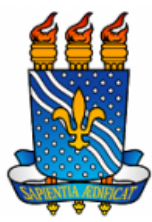

UNIVERSIDADE FEDERAL DA PARAÍBA

Programa de Pós-Graduação em Ciências Jurídicas 


\title{
Estado De Calamidade Pública Enquanto Possibilidade De Limite Circunstancial Implícito De Emenda Constitucional
}

\author{
Roberto Leonardo da Silva Ramos
}

\section{INTRODUÇÃO}

O estado de calamidade pública consiste em um conjunto de acontecimentos danosos que provocam uma anormalidade no funcionamento institucional e na dinâmica relacional da sociedade, ocasionando um estado de crise emergencial. No Brasil, a primeira experiência em nível nacional é o caso do Coronavírus, causador da Covid-19, resultando na decretação do estado de calamidade pública em março de 2020.

A Organização Mundial de Saúde (OMS) reconheceu a proliferação do Coronavírus como pandemia, isso porque o vírus foi detectado na totalidade dos continentes, vindo a ocasionar um caos na saúde, atingindo níveis consideráveis de mortalidade. No Brasil há concomitantemente, a discussão sobre os melhores meios de enfrentamento, dividindo opiniões em decorrência do escasso conhecimento técnico referente ao comportamento do vírus.

No âmbito jurídico, o Poder Judiciário vem sendo provocado para se manifestar sobre inúmeras matérias, a exemplo da legalidade de medidas restritivas ao direito de locomoção, ao fechamento do comércio e, até mesmo, à competência legislativa e administrativa dos entes federativos. Nesse sentido, quantidades significativas de atos normativos são editados, a exemplo de leis, decretos, portarias e, inclusive, uma emenda constitucional. 
Diante desse contexto, busca-se saber a possibilidade de reconhecimento de limite circunstancial implícito ao poder de emenda da Constituição Federal (CF) em casos de estado de calamidade pública. Trata-se de debate quase inexistente e suscitado de modo inédito pelo jurista Ingo Wolfgang Sarlet.

Delimita-se a pesquisa no campo do direito constitucional, lançando mão principalmente de textos autorais de Luís Roberto Barroso, José Joaquim Gomes Canotilho, Gilmar Ferreira Mendes, Boaventura de Sousa Santos, Emmanuel Joseph Sieyès, Lenio Luiz Streck, André Ramos Tavares, além do próprio Ingo Sarlet. A hipótese defendida é pela possibilidade da referida irreformabilidade, sob a condição de poder ocorrer alteração no texto constitucional em situações excepcionais, com vistas ao enfrentamento da causa ensejadora do estado de calamidade pública, sendo defeso inibir direitos consolidados constitucionalmente.

A construção do entendimento proposto, desenvolve-se inicialmente quanto ao poder constituinte e poder constituído, objetivando demonstrar a essência de cada instituto e sua legitimidade, haja vista possuírem a função de positivar normas estruturantes do sistema jurídico, o primeiro se fundamentando na construção valorativa no curso histórico e o segundo, nas disposições expressas e implícitas da ordem constitucional.

Em seguida, discorre-se sobre os limites ao poder de reforma, que, no atual estágio da realidade brasileira, se confunde com o próprio poder de emenda, quais sejam, os limites formal, material (expresso e implícito) e o circunstancial expresso, pondo em evidência ideias essenciais de cada instituto para a construção da tese aqui defendida. Em seguida, aborda-se diretamente a possibilidade de limite circunstancial implícito, particularmente em casos de decretação de calamidade pública.

O instituto em apreço é esmiuçado a partir dos princípios da analogia, da razoabilidade, da proporcionalidade, com a defesa do estado constitucional democrático de direito e dos valores que 
suplantam as dificuldades de reconhecimento da referida irreformabilidade.

\section{CONSIDERAÇÕES ACERCA DO PODER CONSTITUINTE E DO PODER CONSTITUÍDO}

Pretende-se, no corrente capítulo, demonstrar a legitimidade e titularidade do poder constituinte, dados necessários ao entendimento da tese desenvolvida relativa aos limites circunstanciais implícitos às reformas constitucionais. Apesar de se reconhecer a existência de constituição, e por consequência, de poder constituinte desde a origem das primeiras organizações políticas, na presente obra, realiza-se o recorte da teoria do poder constituinte, que alude às instituições do mundo moderno em sua última fase.

As primeiras constituições do período moderno remontam à estadunidense, de 1787, e francesa, de 1791, sendo a primeira de âmbito mais regionalizada visando a desvinculação colonial com a metrópole europeia e a segunda com o escopo universalista, pretendendo ampliar seus princípios fundantes para outros Estados. O pensador e ativista francês Emmanuel Joseph Sieyès em sua obra Qu'est-ce que Le Tiers État?1, traduzida para o português como "A Constituinte Burguesa", introduz o debate referente ao poder constituinte, a partir da teoria política e jurídica, tendo como base a aproximação do Terceiro Estado (burguesia) com a ideia de Nação.

Para Sieyès (2014), o poder constituinte diferencia-se do poder constituído, sendo aquele baseado no direito natural e refletindo a vontade da Nação, detentora da soberania nacional. A Nação, por sua vez, seria materializada na classe burguesa, que, até então, não gozava de prestígio político, mudança ocorrida com as revoluções liberais e a

${ }^{1}$ Publicado originariamente no ano de 1789 . Utilizou-se a $6^{\mathrm{a}}$ edição traduzida no ano de 2014. 
percepção da teoria do poder constituinte moderno. O poder constituído tem seu fundamento e seus limites no poder constituinte, isto é, o seu exercício deve se desenvolver com base em normas previstas na Constituição.

No ordenamento jurídico brasileiro, comumente adota-se a nomenclatura de poder constituinte como poder constituinte originário, e poder constituído como poder constituinte derivado, este se dividindo em poder decorrente, poder constituinte revisional e poder de reforma. Conforme especificado mais adiante, na presente obra adota-se a nomenclatura "poder constituinte" e "poder constituído" (ou "instituído"), sendo o poder reformador, cujas subcategorias são os poderes de emenda e revisão.

O poder constituinte emana da interação volitiva entre os atores sociais, pois se baseia nas exigências e na aceitação por parte da sociedade das normas apresentadas pelos sujeitos formadores de opinião e detentores de espaços que o capacitem para a edição de normas constitucionais. A esse respeito, Luís Roberto Barroso (2018) expõe:

O poder constituinte, como qualquer poder efetivo, envolve a manifestação de vontade de quem o exerce e o consentimento ou a sujeição de quem a ele se submete. Dificilmente será possível falar na vigência de uma Constituição onde haja desobediência ampla e generalizada. $\mathrm{Na}$ sua essência, portanto, o poder constituinte consistente na capacidade de elaborar uma Constituição e de determinar sua observância. (BARROSO, 2018, p. 81)

Sem aceitação popular não há força para se criar uma nova constituição, muito menos sua permanência em vigor, pois a norma fundamental reflete as aspirações sociais, econômicas e políticas de uma geração. Portanto, por mais que detentores do poder político tentem normatizar seus interesses particulares, sem ampla adesão social haverá forte resistência e desobediência significativa dos integrantes da sociedade. Como modo de dificultar ingerências abusivas mascaradas em forma de normas constitucionais, existem previsões de limites aos poderes constituintes e constituídos, como 
será detalhado oportunamente. Então, o poder constituinte tem sua titularidade na soberania nacional (conforme desenvolvido por Emmanuel Joseph Sieyès), baseada na adesão popular, que atribui legitimidade ao exercício da constituinte. Movimento diverso revestese de ilegitimidade, havendo ruptura entre o direito e a sociedade, provocando atritos sociais e a imposição da força física visando a observância das diretrizes normativas. O poder constituinte legítimo é efêmero, sendo uma vez alcançados os seus objetivos, dá lugar ao poder constituído, que atuará com base nas normas postas.

A soberania nacional não se vincula a nenhuma norma preexistente, sendo o poder constituinte pré-constitucional, como reconhece Ingo Wolfgang Sarlet (2017).

A constituição, ao contrário do que ocorre com as normas infraconstitucionais, não extrai o seu fundamento de validade de uma ordem jurídica (formal) superior, mas se estabelece e alcança autoridade jurídica superior (em relação às demais esferas normativas internas do Estado) em função da "vontade" das forças determinantes e representativas da sociedade na qual surge a constituição. É neste sentido que o poder constituinte acaba assumindo a feição de uma categoria pré-constitucional, capaz de, por força de seu poder e de sua autoridade, elaborar e fazer valer uma nova constituição. (SARLET, 2017, p. 98-99)

Assim, o poder constituinte estabelece uma nova ordem constitucional, podendo a critério próprio recepcionar ou não normas constitucionais anteriores, vale dizer, seu fundamento de validade é a soberania nacional, expresso pela vontade popular, não em um momento específico que pode se apresentar ilegítima, mas em uma construção cultural no curso histórico. O exercício do poder constituinte se dá, em regra, pela assembleia constituinte, ou seja, por representantes do povo imbuídos de editar uma carta que expresse os valores da nação.

Apesar de ser comum mencionar o poder constituinte como ilimitado e autônomo, verifica-se que estas atribuições não são absolutas. Emmanuel Sieyès (2014) já reconhecia o direito natural como condicionante ao poder constituinte, ideia que evoluiu no tempo. 
Hodiernamente se podem destacar alguns limites úteis ao objeto da presente análise.

Em termos materiais, localizam-se os condicionantes no campo da legitimidade, e não da legalidade. Para tanto, a assembleia constituinte deve compatibilizar sua produção normativa a preceitos axiológicos prevalentes no corpo social, refletindo uma influência à tradição constitucional. Luís Roberto Barroso (2018) posiciona-se nesse mesmo sentido, conforme exposto abaixo:

O poder constituinte estará sempre condicionado pelos valores sociais e políticos que levaram à sua deflagração e pela ideia de Direito que traz em si. Não se trata de um poder exercido em um vácuo histórico, nem existe norma autônoma em relação à realidade. (BARROSO, 2018, p. 86)

Ocorrendo descompasso entre valores sociais e as normas recém-editadas, não há de se falar em legitimidade e, por consequência, se dá o afastamento do caráter democrático. Também deve haver observância a princípios supranacionais e presentes em cartas internacionais de direitos humanos, a exemplo da Declaração Universal dos Direitos Humanos (1948) e o Pacto de São José da Costa Rica (1969).

Formalmente, isto é, no âmbito do procedimento percorrido desde a convocação da assembleia constituinte até a deliberação, visualiza-se uma fase de autorregulação dos sujeitos ocupantes dos cargos políticos diretamente envolvidos. A título de exemplo, a Constituição Federal de 1988 teve seus elementos formais de edição estabelecidos por uma Emenda $\left(\mathrm{N}^{0} 26 / 1985\right)$ à Constituição de 1967/1969. Os meios a serem percorridos visando a edição da carta constitucional são influenciados pela força transformadora da estrutura política e jurídica até então existente

Todas as ações e limites da assembleia constituinte são condicionados fundamentalmente pela força transformadora emergente dos movimentos sociopolíticos, podendo ser legítima, a exemplo de mudança na estrutura política, ou ilegítima, a exemplo de um golpe de estado. Uma vez estabelecida a nova ordem 
constitucional, surge o poder constituído, comumente denominado de poder constituinte derivado. O referido poder é responsável pela adaptação normativa às novas realidades sociais, evitando-se assim o engessamento constitucional.

Nas palavras de José Joaquim Gomes Canotilho (1993, p. 1.124) "[...] a ideia de superioridade do poder constituinte não pode terminar na ideia de constituição Ideal [...]”, portanto a constituição apesar de servir como instrumento de estabilidade institucional não significa que deverá ser imutável, pelo contrário, o equilíbrio da estrutura política e jurídica é reforçado pela capacidade de mudança constitucional no curso do tempo.

A mudança das normas constitucionais pode se dar de modo informal e formal, como menciona José Afonso da Silva (2005) nos seguintes termos:

\begin{abstract}
A questão terminológica nessa matéria começa pela necessidade de fazer distinção entre mutação constitucional e reforma constitucional. A primeira consiste num processo não formal de mudança das constituições rígidas, por via da tradição, dos costumes, de alterações empíricas e sociológicas, pela interpretação judicial e pelo ordenamento de estatutos que afetem a estrutura orgânica do Estado. A segunda é o processo formal de mudança das constituições rígidas, por meio de atuação de certos órgãos, mediante determinadas formalidades, estabelecidas nas próprias constituições para o exercício do poder reformador. (SILVA, 2005, p. 6162)
\end{abstract}

A mutação constitucional enquadra-se como informal por não alterar o texto da constituição, sendo um exemplo a mudança de interpretação do X, art. 52 da CF pelo STF, já que, ao declarar a inconstitucionalidade em sede incidental, os efeitos da decisão são erga omnes e vinculantes, devendo a Suprema Corte apenas informála ao Senado, para que proceda a publicidade da decisão ${ }^{2}$, não mais havendo discricionariedade do legislativo em suspender ou não a execução da lei declarada inconstitucional.

${ }^{2}$ STF. Plenário. ADI 3406/RJ e ADI 3470/RJ, Rel. Min. Rosa Weber, julgados em 
O segundo modo de mudança é a formal, ocorrendo por meio da reforma constitucional, em que há alteração do conteúdo da Constituição. O termo "reforma" se refere a qualquer alteração do texto constitucional, sendo gênero das espécies emenda e revisão. A emenda 3 é adotada para mudanças específicas, ao passo que a revisão ${ }^{4}$ é mais ampla. Relativamente a essa última, a Constituição Federal de 1988 determinou o prazo de cinco anos após sua promulgação para tal realização, tendo como matéria a forma e o sistema de governo. Atualmente o poder de reforma pátrio a ser desempenhado é apenas por meio de emenda.

Ao tempo em que as mudanças constitucionais são imprescindíveis ao acompanhamento da evolução social, o referido texto não deve se submeter aos oportunismos populistas, pois fragilizariam princípios fundamentais, sendo esses esteios ao estado constitucional democrático de direito. Com base nessa perspectiva, a seguir dispõe-se acerca de limites ao emendismo constitucional e indispensáveis ao entendimento do limite implícito tese da presente pesquisa.

\section{LIMITES AO PODER DE EMENDA CONSTITUCIONAL}

O poder constituinte não possui a capacidade de elaborar uma constituição acabada e imutável ao tempo que não é salutar a edição de novas constituições com regularidade, por isso a importância do poder constituído reformador. Antônio Moreira Maués (2020) dispõe sobre essa matéria nos termos que seguem.

[...] os agentes que exercem o poder constituinte originário reconhecem que sua obra, para ter permanência, precisará

\footnotetext{
${ }^{3}$ Prevista no art. 60 da Constituição Federal de 1988.

4 Prevista no art. $3^{\circ}$ do Ato das Disposições Constitucionais Transitórias da Constituição Federal de 1988.
} 
se adaptar às mudanças sociais. Assim, as normas referentes a reformas constitucionais buscam harmonizar dois objetivos distintos: garantir a estabilidade da constituição, a fim de que as instituições fundamentais do Estado continuem regidas por ela, e garantir a funcionalidade da constituição, a fim de que ela mantenha sua capacidade de regular os conflitos sociais. (MAUÉS, 2020, p. 02)

As reformas, que atualmente no Brasil se restringem ao poder de emenda, possuem essa dupla função, um a estabilidade constitucional e por consequência institucional e dois a adaptabilidade aos contextos sociais emergentes preservando sua eficácia normativa.

O poder constituído tem sua atuação restrita ao estabelecido pelo poder constituinte, sendo sua legitimidade baseada na carta constitucional, dessa maneira, fundamenta-se nos preceitos constitucionais e busca o equilíbrio entre a estabilidade e o disciplinamento das novas realidades. A Constituição, com vistas à não descaracterização dos valores constitucionais sensíveis, previu limites expressos ou tácitos ao poder de emenda, podendo ser formais, materiais e circunstanciais. A seguir, expõe-se sobre cada um, no que interessa ao objeto do texto corrente.

A Constituição brasileira, quanto ao grau de dificuldade de alteração ${ }^{5}$, caracteriza-se pela rigidez, posicionamento majoritário da doutrina, a exemplo de Luís Roberto Barroso (2018), isto é, as alterações feitas em seu texto devem se submeter a um rito mais dificultoso do que o processo legislativo ordinário, estabelecendo um limite formal. Portanto, o art. 60 da CF prevê que a emenda deve ser aprovada, em dois turnos, por 3/5 dos membros de ambas as casas do Congresso Nacional, sendo vedada a reapreciação em mesma sessão legislativa de matéria rejeitada ou prejudicada. A iniciativa de propor uma emenda constitucional é de, pelo menos, um terço dos membros da Câmara dos Deputados ou do Senado Federal, do Presidente da República e de mais da metade das Assembleias Legislativas, cada uma se manifestando por maioria relativa de seus membros.

\footnotetext{
${ }^{5}$ Em relação ao critério de estabilidade, as constituições podem ser rígidas, flexíveis, semirrígidas, a quem se interessar pelo tema, indica-se leitura de Sarlet (2017, p. 64-65).
} 
Deve-se ter atenção à formalidade inicial, ou seja, a legitimidade de propor a emenda se dá a membros de poderes majoritários das esferas estaduais e federal, que comumente precisam praticar atos visando uma afirmação junto a seu eleitorado, garantindo-se, dessa maneira, a permanência em cargos eletivos. Em tempos de instabilidade social ou até mesmo de influência de grupos sociais com ideais disruptivos, podem ocasionar alterações no texto constitucional não condizentes com os princípios sensíveis do ordenamento jurídico, o que deve ser considerado em demandas levadas ao judiciário, poder de natureza contramajoritária.

Há também a categoria de irreformabilidade constitucional dos limites materiais, sendo aquelas normas constitucionais eleitas pelas decisões da assembleia constituinte que devem ser preservadas para manter a essência da constituição e, de modo reflexo, a própria estrutura estatal, sendo denominadas de cláusulas pétreas ou de intangibilidade. Com a previsão da impossibilidade de mudança de determinadas normas constitucionais substancias, levanta-se a questão de como os valores de um determinado período histórico podem vincular gerações futuras ao ponto do poder constituído não poder modificá-los. J. J. Canotilho dispõe o seguinte a esse respeito.

[...] nenhuma constituição pode conter a vida ou parar o vento com as mãos, nenhuma lei constitucional evita o ruir dos muros dos processos históricos, e, consequentemente, as alterações constitucionais, se ela já perdeu a sua força normativa. Mas há também que assegurar a possibilidade de as constituições cumprirem a sua tarefa e esta não é compatível com a completa disponibilidade da constituição pelos órgãos de revisão, designadamente quando o órgão de revisão é o órgão legislativo ordinário. (CANOTILHO, 1993, p. 1.129)

Dessa maneira, não se espera um engessamento constitucional, pelo contrário, uma constituição deve corresponder às necessidades sociais apresentadas no cotidiano da sociedade, mas, de igual modo, sua função também é de resguardar o mínimo de estabilidade e previsibilidade de preceitos basilares do ordenamento jurídico. Luís Roberto Barroso (2018) desenvolve dois fundamentos em relação às 
referidas cláusulas de intangibilidade, que são a identidade constitucional e a defesa do Estado democrático de direito.

A preservação da identidade da constituição é fundamental sob pena de alterá-la substancialmente ao ponto de se obter uma nova constituição por meio do exercício de poder constituído e não pelo poder constituinte, burlando a soberania popular. A Constituição Federal de 1988 prevê expressamente no $\S 4^{\circ}$ do art. 60 um rol de institutos essenciais, a exemplo da forma de estado federativa, sendo assim nenhuma proposta de emenda poderá ser aprovada com o intuito de restabelecer o estado unitário no Brasil.

A defesa do Estado democrático é o segundo fundamento. $\mathrm{O}$ constitucionalismo moderno visa a limitação do poder político e a tutela dos direitos fundamentais, sendo a democracia um valor invariável do Estado de direito. Uma maioria parlamentar transitória não pode se fazer prevalecer sobre preceitos democráticos, afetando o funcionamento do Estado constitucional de direito. Barroso (2018) aponta nesta linha de pensamento.

As cláusulas pétreas ou de intangibilidade são a expressão mais radical de autovinculação ou pré-compromisso, por via do qual a soberania popular limita o seu poder no futuro para proteger a democracia contra o efeito destrutivo das paixões, dos interesses e das tentações. Funcionam, assim, como a reserva moral mínima de um sistema constitucional. (BARROSO, 2018, p. 108)

Logo, a limitação material é a garantia de que a vontade da soberania popular seja observada no curso do tempo, evitando a modificação do regular funcionamento do Estado democrático de direito por aventuras eleitoreiras.

Além das cláusulas pétreas elencadas no $\S 4^{\circ}$ do art. 60 da Constituição Federal, como já exposto, defende-se a existência de limites materiais implícitos, visto que entendimento contrário, em uma realidade de rigidez constitucional, iria fragilizar os institutos essenciais por estarem previstos em locais diversos dos limites expressos. Nesse sentido, entende Barroso (2018, p. 109) que "[...] a presença de cláusulas pétreas no texto não exclui a possibilidade de se 
reconhecer a existência de limites implícitos." sendo também esse o entendimento do $\mathrm{STF}^{6}$, aqui ratificado.

Por se tratar de limites implícitos ao poder constituído, deve-se fazer uma interpretação restritiva de quais normas se amoldam ao instituto em apreço, haja vista que o rol de cláusulas pétreas a ser considerado será determinado de modo imediato pela construção de intérpretes e aplicadores da Constituição, não sendo incomum divergência na análise de determinada matéria, daí o posicionamento cauteloso de Ingo Sarlet (2017), colacionado a seguir.

[...] a construção de uma teoria dos limites implícitos à reforma constitucional apenas pode ser efetuada à luz de determinada ordem constitucional, isto é, do direito constitucional positivo, no sentido de que as limitações implícitas deveriam ser deduzidas diretamente da constituição, considerando-se especialmente os princípios cuja abolição ou restrição poderia implicar a ruptura da própria ordem constitucional. (SARLET, 2017, p. 136)

Destarte, as normas indicadas como limitações implícitas devem estar previstas diretamente na Constituição. Portanto, defendese o reconhecimento de limites materiais implícitos, por ser essa postura imanente ao Estado constitucional democrático de direito, resguardando seus preceitos basilares ao restringir a atuação imprópria do legislador constitucional instituído.

Ao discorrer acerca dos fundamentos do poder constituído, seus limites formais e materiais implícitos, passa-se a desenvolver o instituto dos limites circunstanciais que estão expressos na Constituição, para em seguida abordar diretamente e com base nas considerações ora construídas, a tese defendida da existência de limites circunstanciais implícitos.

\section{ESTADO DE CALAMIDADE PÚBLICA COMO LIMITE CIRCUNSTANCIAL IMPLÍCITO}

${ }^{6}$ STF. Plenário. MS 24.875, Rel. Min. Sepúlveda Pertence, j. 11-5-2006. Data de Publicação: DJ 6-10-2006. 
De início, cumpre mencionar que os limites circunstanciais não se confundem com os limites temporais, posicionamento defendido por Luís Roberto Barroso (2018, p. 103). Já Ingo Wolfgang Sarlet (2017, p. 131) perfilha-se à corrente que entende pela inexistência de diferença entre ambos os institutos, diferentemente do que é seguido no presente texto. Dada a divergência doutrinária mencionada, passam-se a expor a diferença entre ambas as categorias. Quando a restrição ao poder de reforma (aqui se inclui tanto a emenda como revisão) se dá por determinado interregno temporal é o caso da limitação temporal, a exemplo da Constituição francesa de 1791 ao proibir alterações no prazo de quatro anos contados de sua aprovação, mesma previsão contida na Constituição brasileira de 1824. Esse tipo de restrição não é comum entre as constituições, sendo em regra possível serem submetidas a reformas em qualquer tempo.

No Brasil, o STF foi provocado para se manifestar em relação à possibilidade de adiantar a data da revisão constitucional (de 07 de setembro para 21 de abril de 1993) prevista originariamente pelo art. $2^{\circ}$ da ADCT da Constituição de 1998 e modificada pela EC No2/1992, cujo conteúdo era a consulta por meio de plebiscito acerca da forma e do sistema de governo a serem adotados pelo País, devendo a população escolher entre república ou monarquia e presidencialismo ou parlamentarismo, respectivamente. A Corte Suprema decidiu7 pela possibilidade da alteração da referida data, implicando na conclusão de que a norma constitucional questionada não se enquadrava como limitação temporal.

As limitações circunstanciais, por sua vez, segundo Luís Roberto Barroso (2018, p. 104), “[...] são aquelas que impedem a reforma da Constituição em momentos de anormalidade institucional, decorrentes de situações atípicas ou de crise." São restrições cujas finalidades visam proteger os institutos constitucionais em tempos de

${ }^{7}$ STF. ADI: 830 DF, Relator: Min. Moreira Alves, data de julgamento: 14/04/1993, Tribunal Pleno, Data de Publicação: DJ 16/09/1994. 
instabilidade social e política, momentos propícios para alterações desarrazoadas. Estão expressas na Constituição Federal de 1988 no art. $60, \S 1^{\circ}$, e correspondem ao estado de sítio, ao estado de defesa e à intervenção federal. Passa-se a tecer comentários sobre cada um, o que é necessário para fundamentar a tese de existência da limitação circunstancial implícita.

As três hipóteses previstas como limites circunstanciais são instrumentos utilizáveis em momentos de crises institucionais, visando a manutenção ou restauração da normalidade sociopolítica. Os instrumentos em questão devem ser manuseados de modo que sejam necessários e temporários, sob pena de caracterizar excesso das atribuições de quem os exerce, sendo assim, passível de punições de naturezas diversas. Tais medidas, de acordo com o art. 84, IX e X da CF, são de iniciativa do chefe do Poder Executivo, submetendo-se ao controle político do Congresso Nacional, previsão do art. 49, IV da CF, sendo ambos os atos de natureza política.

A primeira hipótese é a intervenção federal, prevista nos art. 34, 35 e 36 da CF. André Ramos Tavares (2017, p. 941) afirma que "O objetivo é a mantença do pacto federativo ou o respeito a elementos considerados, pela Constituição, como essenciais à manutenção de certa "ordem" e permanência das instituições." Sendo assim, mesmo em momentos de crise a finalidade é a estabilidade institucional democrática, evitando abruptas mudanças nas estruturas presentes na Constituição Federal graças à previsão do limite circunstancial.

Nesse norte, o problema ora suscitado corresponde à possibilidade de controle jurisdicional ao instituto em apreço, o que não consta como proibitiva pela Constituição, consequentemente nada impede o Poder Judiciário de realizar controle ao exercício dos instrumentos de crise, desde que provocado, em situações de extrapolação e em consequência de violação ao texto constitucional. A estabilização sociopolítica muitas vezes busca o equilíbrio entre os poderes, não sendo razoável excluir a participação jurisdicional em casos excepcionais. 
A segunda hipótese de momento de crise pontuado é o estado de defesa, que segundo a previsão do caput, art. 136 da $\mathrm{CF}$ visa "preservar ou prontamente restabelecer, em locais restritos e determinados, a ordem pública ou a paz social ameaçadas por grave e iminente instabilidade institucional ou atingidas por calamidades de grandes proporções na natureza.”. Assim a CF autoriza em casos de instabilidade institucional e calamidade com relevantes dimensões na natureza e passíveis de provocar desequilíbrio na ordem pública ou na paz social, poderes excepcionais ao chefe do executivo e por isso a blindagem ao texto constitucional, que não pode ser reformado enquanto durarem as circunstâncias ensejadoras do estado de defesa.

A terceira hipótese de momento de crise é o estado de sítio, prevista no art. 137 da $\mathrm{CF}$, podendo ocorrer nas situações de ineficácia do estado de defesa, em guerras e na agressão armada. Como se vê, medidas excepcionais poderão ser realizadas pelas autoridades competentes e, dadas as circunstâncias de crise o poder constituinte inibiu o exercício do poder constituído, evitando alterações lesivas à ordem jurídica, já que, em momentos de normalidade, seriam de difícil aceitação social.

Logo, os limites circunstancias visam a inibição do poder constituído em situações de crise, objetivando a preservação da vontade do legislador em momentos de normalidade, pressupondo que houve ampla análise das matérias sem interferências extraordinárias. Dessa maneira, os interesses da soberania nacional expressos no texto constitucional são mantidos e protegidos dos oportunismos comuns em tempos de instabilidades.

A questão que se coloca é saber a possibilidade de reconhecimento da existência de limite circunstancial em caso de decretação de estado de calamidade pública, mesmo sem haver expressa previsão na Constituição Federal. Em outras palavras, podese considerar a existência de limite circunstancial implícito? Para responder ao problema, parte-se dos pontos de contato entre a calamidade pública e as situações que dão azo aos limites circunstanciais explícitos, desenvolvidos a seguir. 
A ideia de calamidade pública tem como referência a previsão do Decreto $\mathrm{n}^{0} 7.257 / 2010$, art. $2^{0}$, IV ao dispor que é a "situação anormal, provocada por desastres, causando danos e prejuízos que impliquem o comprometimento substancial da capacidade de resposta do poder público do ente atingido;". Destarte, entende-se calamidade pública como um acontecimento natural, cujos efeitos são suportados difusamente pela sociedade; trata-se de uma realidade fática com projeções jurídicas. Seu advento se apresenta como um desafio aos governantes, pois dada a situação emergencial devem providenciar medidas profiláticas, combativas e/ou reparativas visando proteger a população. Exemplo é a proliferação do Coronavírus, causador da Covid-19, com repercussão mundial e registro oficial do primeiro caso no Brasil no início de 2020.

O modo de enfretamento de uma calamidade pública não está prevista pela Constituição Federal nem, pela legislação infraconstitucional, sendo uma situação aberta, já que ocasionada por diversidade de circunstancias, o que a diferencia das causas ensejadoras dos limites circunstanciais expressos. Entretanto a situação de crise é instaurada de forma semelhante, haja vista um estado de anormalidade social se apresentar, com reflexo no funcionamento das instituições.

Em sede de exemplificação, cita-se o caso da Covid-19, que por ser causada por um vírus, sua transmissão ocorre de inúmeras formas e de difícil controle ${ }^{8}$. Some-se a isso o fato de ser um vírus de nova variação e de os especialistas ainda não dominarem integralmente seu modo de transmissão, seu poder ofensivo nem seu tratamento. Logo, dados os efeitos letais e a falta de conhecimento referente à doença, medidas drásticas estão sendo defendidas pelas autoridades sanitárias e seguidas quase que pela totalidade dos governantes. Restrição à locomoção das pessoas, ao fechamento do comércio e dos órgãos públicos são exemplos de medidas realizadas que afetam

${ }^{8}$ A rápida proliferação do Coronavírus é reconhecida pela OMS, que no mês de agosto de 2020 contabilizou 20 milhões de casos no mundo e 750 mil mortes, conforme link a seguir: https://news.un.org/pt/story/2020/08/1722692 
sensivelmente a dinâmica da sociedade, implicando em crise econômica e política.

No Brasil, um verdadeiro embate ocorre acerca das medidas a serem implementadas pelos governantes, havendo uma corrente seguida pela quase totalidade de governadores e prefeitos que se posicionam pelas orientações de organismos internacionais, principalmente a Organização Mundial de Saúde (OMS); outra corrente, liderada pelo governo federal, opta por negar o potencial danoso da pandemia. O resultado desse conflito é a fragilização das medidas protetivas, ampliando casos de infectados e mortes, pois parcela da população decide em não aderir voluntariamente às orientações baseadas em recomendações de especialistas.

Identifica-se, assim, em ambas as estratégias de enfrentamento a dualidade de visão a respeito da estrutura social, de um lado a coletivista e de outro a individualista. Referente a esse dualismo, Sandra Caponi (2020) expõe o seguinte:

\begin{abstract}
A primeira [coletivista], é aquela que perante a ausência de vacinas e medicamentos investe maciçamente nos únicos médios [sic] de proteção existentes, propondo o isolamento social obrigatório e criando auxílios e redes de proteção para as populações vulneráveis. Mostrando a necessidade de restituir o estado de bem-estar tão fragilizado em todo o mundo. A segunda [individualista], é a adotada no Brasil, uma estratégia negacionista que continua cumprindo fielmente com as exigências do neoliberalismo, como se absolutamente nada devesse mudar com a pandemia. (CAPONI, 2020, p. 218)
\end{abstract}

$\mathrm{Na}$ realidade brasileira ocorre a superposição de crises sanitárias, políticas e econômicas, pois em um momento emergencial como este, o conhecimento técnico não se superpõe totalmente ao negacionismo, criando uma falsa disputa entre prestigiar vidas ou proteger a economia, quando, na verdade, ambos os fatores devem coexistir. Essa divisão culmina em maior exposição das classes populares ao vírus, pois a ausência do Estado implica na mercantilização de direitos sociais, recaindo sobre a população economicamente vulnerável as consequências mais danosas da Covid- 
199. É um contexto de instabilidade, revelando o modelo socioeconômico implementado no Brasil como um modo de possível fragilização de valores constitucionalmente tutelados, caso não haja uma tutela circunstancial excepcional ao texto da Constituição Federal.

É fundamental a presença do Estado na atuação de enfrentamento da calamidade pública, devendo-se levar em consideração critérios técnicos ${ }^{10}$. Ao tempo em que as ações estatais são primordiais, os governantes sentem-se receosos de que seus atos causem responsabilizações cíveis, administrativas, políticas e até criminais, daí a Lei $n^{0}$ 101/2000 (Lei de Responsabilidade Fiscal LRF) prever a suspensão de prazos e a dispensa de metas fiscais, agilizando o enfrentamento das causas da calamidade. A LRF, em seu art. 65, condiciona ao Poder Legislativo o reconhecimento do estado de calamidade pública, autorizando o executivo a realizar medidas com a celeridade e as despesas que a situação exigir. Facilmente percebe-se que se está diante de uma realidade de crise, com instituições atuando de modo excepcional no contexto de clamor social e com divergências no que diz respeito aos mecanismos de enfrentamentos diretos e reflexos.

No correspondente à produção legislativa, especificamente no caso da Covid-19, ressalta-se o decreto legislativo necessário à decretação da calamidade pública pioneira na esfera federal ${ }^{11}$, de uma emenda constitucional ${ }^{12}$, a aprovação de leis e atos normativos em geral nas esferas federais ${ }^{13}$, estaduais ${ }^{14}$ e municipais ${ }^{15}$, objetivando

\footnotetext{
${ }^{9}$ Estudo realizado por pesquisadores (MACIEL; CASTRO-SILVA; FARIAS, 2020) da Universidade Federal do Ceará (UFC) apontam que a incidência da Covid-19, no estado do Ceará, se dá com maior intensidade em áreas populacionais com baixo índices de desenvolvimento humano (IDHM).

10 Estudo da ONU (2020) aponta que renda básica temporária para população carente contribui para o retardo na disseminação do Coronavírus. Ação estatal que realiza essa medida prestigia o conhecimento científico, preserva vidas e fomenta a economia.

${ }^{11}$ Decreto Legislativo No 6 de 20 de março de 2020.

${ }^{12}$ Emenda Constitucional $N^{\circ} 6$ de 07 de maio de 2020.

${ }^{13}$ A título exemplificativo a Lei Complementar $\mathrm{N}^{\circ} 173$, de 27/05/2020.

${ }^{14}$ A título exemplificativo o Decreto $N^{\circ} 40.122$, de 13/03/2020 do Poder Executivo do Estado da Paraíba.

${ }^{15}$ A título exemplificativo o Decreto $N^{\circ}$ 9.460, de 17 de março de 2020 do Poder Executivo do Município de João Pessoa.
} 
disciplinar ações combativas, além das condutas comissivas e omissivas do executivo comumente levadas ao crivo do Poder Judiciário ${ }^{16}$. Percebe-se que é uma realidade em que facilmente os poderes procedem a ajustes administrativos e legislativos os quais, em situação de normalidade não seriam sequer sugeridos.

Diante da instabilidade imposta pelas causas da decretação do estado de calamidade pública, torna-se temerosa a alteração do texto constitucional ao tempo que pode também ser necessária ao enfretamento da situação. Ingo Wolfgang Sarlet e Adriano Sant'Ana Pedra (2020) suscitam o debate e reconhecem a dificuldade de reconhecer a existência de limite circunstancial implícito, haja vista que o intuito de proteger a Constituição pode levar à inibição do regular exercício democrático das casas legislativas.

A razoabilidade é medida que deve orientar o pensamento jurídico, já que posicionamentos absolutistas podem gerar dificuldades hermenêuticas e, reflexamente, levar a prejuízos no enfretamento dos casos que são colocados à solução. Neste contexto, o reconhecimento dos limites circunstanciais implícitos nos parece viável, podendo haver sua relativização caso haja a ponderação da necessidade de alteração constitucional na busca de superação da calamidade pública, buscando sempre a proporcionalidade das medidas. Nesse sentido, Lenio Luiz Streck (1999) discorre.

\begin{abstract}
Assim, há violação ao princípio da proporcionalidade, com ocorrência de arbítrio, toda vez que os meios destinados a realizar um fim não são por si mesmos apropriados e/ou quando a desproporção entre meios e fim é particularmente evidente. (STRECK, 1999, p. 222)
\end{abstract}

Desta feita, a atuação do legislador torna-se desproporcional ao propor emenda à Constituição tendente a suprimir valores historicamente conquistados e sem relação de causalidade ao enfretamento da calamidade pública, o que envolve a necessidade de

${ }^{16}$ Levantamento realizado pelo Insper aponta que 165 mil decisões relacionadas à Covid-19 foram prolatadas no Brasil no primeiro semestre de 2020. Informações no link: https://www.insper.edu.br/conhecimento/direito/decisoes-judiciais-relacionadas-a-covid19-ja-somam-165-mil/ 
reconhecer um limite ao reformismo constitucional. O fato de não haver a previsão expressa ao instituto em apreço não é inibidor de sua existência, pois estão sendo aplicados princípios constitucionais na tutela de seus próprios institutos. Por analogia, pode-se recorrer ao raciocínio de Lenio Streck (1999) ao reconhecer que princípios constitucionais explícitos ou implícitos são suficientes para combater decisões políticas que impliquem violações constitucionais, conforme transcrito a seguir.

Desse modo, mediante a utilização da principiologia constitucional (explícita ou implícita), é possível combater alterações feitas por maiorias políticas eventuais, que, legislando na contramão da programaticidade constitucional, retiram (ou tentam retirar) conquistas da sociedade. (STRECK, 1999, p. 223) [destaque do original]

Com isso, as conquistas sociais não devem ser objeto de perseguição, tendo em vista atuação legislativa de maiorias momentâneas, oportunismo fácil em tempos de instabilidade como o da decretação de estado de calamidade pública. Com essa construção interpretativa sistemática, evidencia-se despicienda a previsão expressa da limitação que é objeto da presente análise. Ademais, conforme já desenvolvido neste texto, o ordenamento jurídico reconhece outra categoria de limites implícitos que são as limitações materiais, o que analogamente autoriza às restrições circunstanciais.

$\mathrm{O}$ exercício da democracia ao pretender reformar a $\mathrm{CF}$, não pode ser fundamento de violação a institutos consolidados, sendo imprescindível a aplicação de limites circunstanciais implícitos em casos de calamidade pública e a depender do caso concreto. Outro não é o entendimento de Ingor Sarlet e Adriano Pedra (2020).

Daí a importância de considerar que a ocorrência de uma pandemia - acompanhada da decretação de estado de calamidade e de importantes medidas restritivas de direitos, inclusive de algumas liberdades fundamentais, pode constituir uma limitação circunstancial implícita ao poder reformador, acionando os efeitos jurídicos respectivos. [...] ainda que em caráter excepcionalíssimo, é possível sustentar a existência de limites circunstanciais implícitos, como é o caso, a depender das circunstâncias 
concretas, do estado de calamidade pública. (SARLET; PEDRA, 2020. n. p.)

A limitação da alteração do texto constitucional prevalece enquanto durar a dinâmica social excepcional capaz de distorcer o funcionamento legítimo das casas legislativas, podendo em tempos de normalidade haver retomada das discussões das matérias pretendidas e limitadas em momentos de crise. Deste modo, não há que se falar em pretenso tolhimento do exercício do Poder Legislativo em matérias constitucionais, pelo contrário, garante-se $\mathrm{o}$ seu regular funcionamento.

Outrossim, argumentos de que medidas extraordinárias em tempos de crise seriam antidemocráticas não se mostram verdadeiros, haja vista em um estado de exceção poderem ocorrer tanto condutas autocráticas como democráticas, sendo um exercício desejável o de "[...] distinguir no futuro não apenas entre Estado democrático e Estado de exceção, mas também entre Estado de excepção democrático e Estado de excepção anti-democrático." (SANTOS, 2020. p. 14). São parâmetros para distingui-las a análise da circunstância a ser superada e a razoabilidade dos instrumentos jurídicos combativos.

Ademais, o poder constituído possui legitimidade na ordem constitucional, considerando tanto os princípios expressos quanto os implícitos, sendo ilegítimo o seu exercício fundamentado em apelos populistas efêmeros, caso contrário, haveria a manifestação do poder constituinte travestida de poder instituído, o que não é aceitável em um estado constitucional democrático de direito.

Conforme discorrido na seção 2 do presente texto, até mesmo o poder constituinte se submete a limites, que por motivos óbvios são implícitos ao se tratar de um poder pré-constitucional e sem vinculação a texto normativo interno. Não se admite do exercício da assembleia constituinte a edição de normas em desacordo com valores internacionais balizadores de direitos humanos. Analogamente, se o poder constituinte é o fundamento do poder constituído e possuem 
limites implícitos, o mesmo raciocínio é aceitável ao poder de emenda que é espécie do gênero poder constituído.

A despeito de defender-se a restrição ao emendismo constitucional em tempos de calamidade pública, a referida limitação não seria de modo absoluto, como ocorre nos estados de sítio, de defesa e intervenção federal, mas que a depender da necessidade haja alguma alteração pontal e temporária ao texto constitucional, sendo este o posicionamento de Sarlet e Pedra (2020), exposto a seguir.

[...] na hipótese de se admitir limites circunstanciais implícitos, faz sentido (inclusive em homenagem ao primado da soberania popular) que, a depender do caso, pudessem ser permitidas emendas pontuais absolutamente indispensáveis para resolver problemas de largo impacto, em especial para a proteção de direitos e garantias fundamentais, mas sempre em caráter temporário, destinadas a perder a eficácia uma vez superado o período de exceção que as motivou, eventualmente passíveis de chancela posterior observados os rigores (limites) formal e materiais legitimadores de uma emenda constitucional. (SARLET; PEDRA, 2020, n. p.)

Durante a vigência do estado de calamidade pública da Covid19 o Congresso Nacional aprovou a Emenda Constitucional $\mathrm{N}^{\circ}$ 106, em o7 de maio de 2020, cuja ementa "institui regime extraordinário fiscal, financeiro e de contratações para enfretamento de calamidade pública nacional decorrente de pandemia". As medidas a serem adotadas visam o enfretamento das causas da calamidade pública e enquanto ela durar.

Apesar do entendimento de aceitação de reforma em caráter excepcional, o ideal é o seu não uso, isto em decorrência da observância dos ritos procedimentais para aprovação de uma emenda, comumente morosos, podendo tornar inócuas as medidas previstas, além da possibilidade de violar normas consolidadas na Constituição, dado o momento de instabilidade, conforme já exposto. Nesta linha de raciocínio, pode-se, de imediato, entender que o limite circunstancial implícito é um entrave ao confrontamento da situação calamitosa, pensamento incompatível com uma interpretação sistêmica da Constituição. 
Essa linha de raciocínio é construída com base no pensamento de que estabilidade jurídica é alcançada principalmente pelo direito positivo, somada à constante tensão entre normas constitucionais e efetivação de direitos sociais. A primeira, porque se transmite a ideia de lei posta enquanto garantia de estabilidade jurídica, já a segunda dada aos escassos recursos públicos para a promoção do bem-estar social da população, comumente denominado de reserva do financeiramente possível, o que se agigante frente a crises como a calamidade pública, a exemplo da Covid-19, tendente a diminuir arrecadação tributária oriunda da necessidade de fechamento ou restrição do funcionamento de consideráveis setores da atividade econômica.

Entretanto, espera-se, com a limitação implícita do poder de emenda defendida no presente texto, a compatibilização do texto constitucional com a realidade emergencial, suprindo-se assim a necessidade de enfretamento da situação de crise e preservando-se os direitos já consolidados no texto constitucional. Tal raciocínio supera o formalismo positivista e desconstrói o pseudo-antagonismo entre Constituição Federal e a efetivação de direitos constitucionalmente consagrados.

Esse raciocínio apresenta-se viável, visto que a Constituição Federal deve ser interpretada de modo ampliado para conformar situações presentes e não previstas expressamente em seu texto, devendo ser considerada a harmonia principiológica estruturante do ordenamento jurídico. Neste mesmo sentido, ao analisar a calamidade pública causada pela Covid-19, Gilmar Ferreira Mendes (2020) destaca.

Em meio a esse complexo quadro, parece evidente que as normas jurídicas soam, em um ponto de vista estritamente pragmático, um mero detalhe no debate sobre a aprovação de medidas essenciais ao combate a uma epidemia que se alastra em progressão geométrica e vem vitimando milhares de pessoas pelo mundo. Entretanto, mesmo nesses momentos, as normas jurídicas - em especial a Constituição - não podem ser encaradas como um obstáculo, mas como um caminho necessário e seguro para a solução da crise. É fundamental prezar pela compatibilização de aparentes contradições e abertura à 
busca por alternativas a uma leitura fria e seca da lei, distante de uma realidade que, muitas vezes, não poderia sequer ser imaginada pelo legislador ou pelo constituinte. (MENDES, 2020, n. p.)

O reconhecimento da possibilidade de limitação circunstancial implícita em casos de decretação de calamidade pública é um instrumento desestimulador da ânsia legislativa em transmitir a falsa noção de que a produção de novas normas inclusive a alteração do texto constitucional são respostas às demandas sociais. A irreformabilidade ora defendida, ao fim, cuida da preservação de princípios constitucionais sensíveis e do aumento da responsabilidade dos gestores em administrar a situação de crise com mais empenho e efetivas respostas à população atingida.

\section{CONCLUSÃo}

Situações de crise trazem para a sociedade ocorrências a serem superadas que nos fazem refletir acerca do funcionamento das instituições e por consequência conhecê-las em sua real formatação. $\mathrm{O}$ presente texto trata de saber se há ou não a possibilidade do reconhecimento de limite circunstancial implícito ao poder de emenda da Constituição Federal aos casos que houver decretação do estado de calamidade pública, utilizando como exemplo marcante e único até a presente data a propagação do Coronavírus causador da Covid-19.

O paralelo entre poder constituinte e poder constituído é imprescindível ao tema suscitado, pois são institutos criadores e modificadores de constituições. O primeiro é uma força criadora com legitimidade na dinâmica social, expressando valores a serem materializados em uma carta que irá estruturar as relações da sociedade. Já o segundo, representa o exercício de adaptação da carta constitucional aos novos tempos, evitando o engessamento do texto da 
constituição, tendo seu fundamento de validade as normas preexistentes.

Comumente, o poder constituinte é caracterizado como ilimitado e autônomo, não se demonstrando um entendimento mais atualizado, visto que a assembleia constituinte ao exercer seu múnus de editar a constituição, deve observar valores da tradição constitucional desenvolvidos no curso da história, em razão de se estar elaborando um novo texto regulamentador e não uma ruptura com a tradição cultural do Estado, sob pena de se manifestar não um movimento democrático, mas uma expressão autocrática impositiva de vertentes normativas em desacordo com as ideias pretendidas pela sociedade.

Outros limites são os princípios supranacionais norteadores de instrumentos normativos internacionais, haja vista os Estados estarem inseridos em relações de interesses mútuos, portanto não há fundamento para uma constituição garantir a degradação ambiental ou trabalho análogo ao de escravo, por serem ações combatidas no âmbito internacional e cuja defesa implicaria em consequências políticas e econômicas negativas com os demais países.

O poder constituído possui limites ao seu exercício previsto expressamente na Constituição Federal, sendo restrições que interessa ao presente artigo as de cunho formal, material e circunstancial. Para alterar a Constituição Federal é necessário seguir procedimento mais rigoroso do que a edição de leis infraconstitucionais, caso contrário a mudança será nula, são as limitações formais. Ao legislador é defeso alterar o texto constitucional tendente a abolir conteúdos específicos, sendo aqueles expressos no $\S 4^{\circ}$ do art. 60 e outros implícitos e diluídos na Constituição Federal, são as limitações materiais. Essas restrições manifestam a defesa da vontade da soberania popular, prestigiando o Estado constitucional democrático de direito.

Os limites circunstanciais são situações impeditivas de reforma constitucional pela ocorrência de crises que impliquem no funcionamento anormal das instituições, sendo a decretação de intervenção federal, estado de defesa e estado de sítio. A intervenção 
federal tem a finalidade de preservar o pacto federativo, atuando junto a anormalidade organizacional, o que, ao fim, garante o regular funcionamento do estado democrático de direito. $\mathrm{O}$ estado de defesa objetiva a preservação ou restabelecimento da ordem pública e a paz social. O estado de sítio pode ser decretado em situações beligerantes ou no insucesso do estado de defesa. As três hipóteses visam a irreformabilidade da $\mathrm{CF}$ enquanto houver a instabilidade social provocada por uma crise específica que desafia cada instrumento apresentado.

O problema suscitado é a possibilidade ou não de reconhecer a existência de limite circunstancial implícito em casos de calamidade pública. Argumentou-se que a crise instaurada pelas causas das restrições circunstanciais possui identidade com a calamidade pública, pois alteram sensivelmente o funcionamento das instituições. Discorreu-se sobre os princípios da razoabilidade e proporcionalidade como inerentes ao seu reconhecimento, implicando na preservação principiológica do texto constitucional em tempos de crise. É sabido que, em situações de anormalidade da dinâmica social, o apelo populista influencia mais facilmente a sociedade, o que pode gerar rupturas antidemocráticas sob o amparo de uma pseudolegitimidade.

A alteração no texto da constituição em momentos de instabilidade pode caracterizar o exercício do poder constituinte mascarado de poder constituído, isso por faltar reflexões adequadas acerca da realidade vivenciada, ocasionando em ações deslegitimadas e antidemocráticas. É em momentos de anormalidade que a Constituição Federal mais deve ser protegida de mudanças, pois os valores presentes no texto constitucional são a própria superação das crises apresentadas.

Considera-se o poder constituinte a maior expressão da soberania nacional e, ainda assim, possuir limites já pontuados anteriormente, sendo naturalmente implícitos. Como a própria criação do texto constitucional se submete a restrições implícitas, além do poder constituído relativa a restrições materiais, por analogia o 
limite circunstancial não deve encontrar óbice ao reconhecimento de situações implícitas que impliquem em irreformabilidade.

A limitação circunstancial implícita, diferentemente da expressa, não deve ser absoluta, devendo o caso concreto ser analisado, sendo permitida alteração no texto constitucional caso esteja presente a necessidade diretamente vinculada ao enfretamento da causa ensejadora do estado de calamidade pública, o que deve ser considerado em hipótese excepcional.

Portanto, a Constituição Federal não deve ser vista como um entrave ao enfrentamento da calamidade, pelo contrário, seus dispositivos devem ser encarados de modo amplo o suficiente para viabilizar soluções surgidas na atualidade e não previstas no passado. De modo que, a compatibilização entre texto constitucional e demandas sociais devem ser buscadas pelas autoridades competentes, não sendo empecilho para o reconhecimento da existência de limite circunstancial implícito em casos de calamidade pública.

Assim, entende-se pela possibilidade da irreformabilidade da Constituição Federal ora defendida, reforçada pelo fato de possuir dúplice função, quais sejam, a primeira a preservação dos preceitos constitucionais e a segunda a provocação do senso de responsabilidade de maior grandeza frente às autoridades, que em vez de apresentar falsas respostas com aprovação de normas inócuas irão enfrentar a crise com ações efetivas.

Data de Submissão: 30/07/2020

Data de Aprovação: 22/10/2020

Processo de Avaliação: double blind peer review

Editor Geral: Jailton Macena de Araújo 
Editor de Área: Jailton Macena de Araújo

Assistente Editorial: Bruna Agra de Medeiros

\section{REFERÊNCIAS}

BARROSO, Luís Roberto. Curso de direito constitucional: os conceitos fundamentais e a construção do novo modelo. $7^{\mathrm{a}}$ Edição. São Paulo: Saraiva, 2018.

CANOTILHO, José Joaquim Gomes. Direito Constitucional. $6^{\text {a }}$ Edição. Coimbra: Livraria Almedina, 1993.

CAPONI, Sandra. Covid-19 no Brasil: entre o negacionismo e a razão neoliberal. Estudos Avançados, p. 209 - 223. 2020. Disponível em: https://www.scielo.br/pdf/ea/v34n99/1806-9592-ea-34-99209.pdf. Acessado em: 10 de jun. de 2020.

CASTIEL, Luis David. Ensaio sobre a pandemência quando personagens e micróbios da ficção-científica saem do filme e invadem o planeta - um acompanhamento critico de enunciados sobre a covid-19 em meios de comunicação leigos e técnicos. Observatório da Medicina. p.1-75, 2020. Disponível em: http://observatoriodamedicina.ensp.fiocruz.br/wpcontent/uploads/2020/05/ENSAIO-SOBRE-APANDEM\%C3\%8ANCIA.pdf. Acesso em: 15 de jun. de 2020.

\section{INSPER. Decisões judiciais relacionadas à Covid-19 já} somam 165 mil. 2020. Disponível em:

https://www.insper.edu.br/conhecimento/direito/decisoes-judiciaisrelacionadas-a-covid-19-ja-somam-165-mil/. Acesso em: 15 de jun. de 2020.

MACIEL, Jacques Antônio Cavalcante; CASTRO-SILVA, Igor Luco; FARIAS, Mariana Ramalho de. Análise inicial da correlação espacial entre a incidência de COVID-19 e o desenvolvimento humano nos municípios do estado do Ceará no Brasil. Revista Brasileira de Epidemiologia, p.1-17, 2020. Disponível em: https://scielosp.org/pdf/rbepid/2020.v23/e200057/pt. Acesso em: 14 de jul. de 2020.

MAUÉS, Antônio Moreira. 30 anos da Constituição, 30 anos de reforma constitucional. Revista Direito GV, 2020. Disponível em: file://C:/Users/ROBERT 1/AppData/Local/Temp/81673-1742891-PB.pdf. Acesso em: 05 de maio de 2020.

MENDES, Gilmar Ferreira. Curso de Direito Constitucional. $13^{\text {a }}$ Edição. São Paulo: Saraiva, 2018. 
MENDES, Gilmar Ferreira. Jurisprudência de crise e pensamento do possível: caminhos constitucionais. Consultor Jurídico, 2020. Disponível em: https://www.conjur.com.br/2020-abr11/observatorio-constitucional-jurisprudencia-crise-pensamentopossivel-caminhos-solucoes-constitucionais. Acesso em: 20 de maio de 2020.

OLIVEIRA, Rafael Carvalho Rezende. Estado de necessidade administrativo e poder de polícia: o caso do novo coronavírus. Revista Brasileira de Direito Público - RBDP. p. 9-23, 2020. Disponível em:

https://www.prefeitura.sp.gov.br/cidade/secretarias/upload/CEJUR \%20-

\%20PGM/CEJUR\%20Clipping/4\%c2\%aа\%20Edi\%c3\%a7\%c3\%а30/ Artigos/4.pdf. Acesso em: 06 de maio de 2020.

ONU. Mundo pode atingir 20 milhões de casos de Covid-19 ainda esta semana, 2020. Disponível em https://news.un.org/pt/story/2020/08/1722692. Acesso em: o9 set. de 2020

ONU. Renda básica temporária pode retardar disseminação da COVID-19, PNUD. 2020. Disponível em:

https://nacoesunidas.org/renda-basica-temporaria-pode-retardardisseminacao-da-covid-19-diz-pnud/. Acesso em: 24 jul. de 2020.

SANTOS, Boaventura de Sousa. A cruel pedagogia do vírus. Coimbra: Edições Almedina, 2020.

SARLET, Ingo Wolfgang; MARINONI, Luiz Guilherme; MITIDIERO, Daniel. Curso de direito constitucional. São Paulo: Saraiva, 2017.

SARLET, Ingo Wolfgang; PEDRA, Adriano Sant'Ana. Democracia e "emendismo" constitucional em tempos de pandemia. Consultor Jurídico, 2020. Disponível em: https://www.conjur.com.br/2020abr-26/democracia-emendismo-constitucional-tempos-pandemia. Acesso em: 13 de maio de 2020.

SARLET, Ingo Wolfgang. Reformas constitucionais, limites circunstanciais ou self restraint legislativo? Consultor Jurídico, 2017. Disponível em: https://www.conjur.com.br/2017-mai19/reformas-constitucionais-limites-circunstanciais-ou-selfrestraint. Acesso em: 18 de maio de 2020.

SIEYÈS, Emmanuel Joseph. A constituinte burguesa. Tradução: Norma Azevedo. 6a Edição. Rio de Janeiro: Freitas Bastos, 2014.

SILVA, José Afonso da. Curso de direito constitucional positivo. $25^{\text {a }}$ Edição. São Paulo: Malheiros Editores, 2005. 
STRECK, Lenio Luiz. Hermenêutica jurídica e(m) crise: um exploração hermenêutica da construção do direito. Porto Alegre: Livraria do Advogado, 1999.

TAVARES, André Ramos. Curso de direito constitucional. $15^{\text {a }}$ Edição. São Paulo: Saraiva, 2017.

ZOUEV, Alexandre. Covid-19 e o Estado de direito. Organização das Nações Unidas (ONU), 2020. Disponível em:

https://nacoesunidas.org/artigo-covid-19-e-o-estado-de-direito/. Acesso em: 05 jul. de 2020. 


\title{
The State Of Public Calamity While Possibility Of Implicit Circumstancial Limit Of Constitutional Amendment
}

\author{
Roberto Leonardo da Silva Ramos
}

\begin{abstract}
The state of Public Calamity was decreed for the first time, in Brazil, at the national level, in March 2020, due to the proliferation of the virus that causes Covid-19. Social dynamics are sensibly affected, given the restrictions established by the Public Power at the federal, state and municipal levels. In order to regulate the new reality, there is ample normative production, such as laws, decrees and, even, constitutional amendment, as well as the judicialization of issues pertinent to facing this Public Health emergency, establishing an institutional crisis. In this context, it was asked about the possibility of recognizing an implicit circumstantial limit to the power to amend the Constitution, especially in cases of decree of the state of public calamity. The article used the deductive approach method, comparative, bibliographic and documentary procedures, constituting a study in the constitutional area, based on normative acts, jurisprudence and doctrines. It started with the institutes of the constituting and constituted powers, showing their expressed and implicit limits as effective instruments in the maintenance of a constitutional order that corresponds to the expectations of popular sovereignty, to conclude by the possibility of the implicit circumstantial irreformability of the Federal Constitution under the state of São Paulo. Public calamity.
\end{abstract}

Keywords: Constitutional amendment. Public calamity. Implicit circumstantial limit.

DOI: https://doi.org/10.22478/ufpb.1678-2593.2021v20n43.54235

Conteúdo sob licença Creative Commons: Attribuition-NonCommercial-NoDerivative 4.0 International (CC BY-NC-ND 4.0) 